\title{
OCORRÊNCIA DE CORPOS SILICOSOS EM HORIZONTES SUPERFICIAIS DE SOLOS DE DIFERENTES $\operatorname{ECOSSISTEMAS}^{(1)}$
}

\author{
Liovando Marciano da Costa ${ }^{(2)}$, Roseilton Fernandes dos $\operatorname{Santos}^{(3)}$, \\ Carlos Ernesto G.R. Schaefer ${ }^{(2)}$, Ana Maria Souza dos Santos \\ Moreau $^{(4)}$ \& Mauricio Santana Moreau ${ }^{(4)}$
}

\begin{abstract}
RESUMO
O entendimento dos processos que causam as diferentes distribuições de corpos silicosos no solo é essencial para a interpretação dos possíveis fatores ambientais responsáveis pela estabilidade deles, deposição de sedimentos, formação de paleossolos e para análise de sítios arqueológicos. Assim, a presente pesquisa objetivou identificar a ocorrência de corpos silicosos encontrados em horizontes superficiais de solos oriundos de diferentes ecossistemas terrestres. Amostras de horizonte superficial de 10 perfis de solo foram coletadas e queimadas em mufla, para remoção da matéria orgânica. Posteriormente, as amostras foram tratadas com HCl $10 \mathrm{cL} \mathrm{L}^{-1}$, para remoção das impurezas contidas na cinza. A fração silte foi obtida por sedimentação, usando o procedimento de análise granulométrica. A maior parte dos corpos silicosos em solos encontra-se na fração silte. Dessa fração, montaram-se lâminas, utilizando óleo de imersão tipo A para identificação dos corpos silicosos em microscópio óptico. A análise dos resultados permitiu observar a variedade de formas e abundância de corpos silicosos nos solos estudados, sendo mais abundantes e diversificados no solo desenvolvido de quartzito. Nos Latossolos, não houve diferença em abundância de fitólitos em relação aos solos dos biomas do Cerrado, Mata Atlântica e Caatinga.
\end{abstract}

Termos de indexação: fitólitos, opala, sílica biogênica, sílica.

(1) Recebido para publicação em julho de 2009 e aprovado em março de 2010.

(2) Professores do Departamento de Solos da Universidade Federal de Viçosa - UFV. CEP 36571-000 Viçosa (MG). Bolsistas do CNPq. E-mail: liovandomc@yahoo.com.br

(3) Professor do Departamento de Solos e Engenharia Rural, Universidade Federal da Paraíba - UFPA. Centro de Ciências Agrárias - Campus III. Campus Universitário/DSER, CEP 58397-000 Areia ( PB). E-mail: roscilton_santos@yahoo.com.br

(4) Professor do Departamento de Ciências Agrárias e Ambientais, Universidade Estadual de Santa Cruz - UESC. Km 16, Rodovia Ilhéus/Itabuna, CEP 45650-000 Ilhéus (BA). E-mail: amoreau@uesc.br e mmoreau@uesc.br 


\title{
SUMMARY: OCCURRENCE OF SILICA BODIES IN SURFACE HORIZONS OF SOILS IN DIFFERENT ECOSYSTEMS
}

\begin{abstract}
The understanding of the processes that cause the varied distribution of silica bodies in soils is essential for the interpretation of the possible environmental factors related to their stability, sediment deposition, paleosol formation and for the analysis of archaeological sites. Thus, this study had the objective of identifying and characterizing the silica bodies morphology from surface soil horizons collected at different terrestrial ecosystems. Samples of surface horizons were collected from 10 soil profiles and heated in a muffle furnace to remove organic matter. Thereafter the samples were treated with $\mathrm{HCl} 10 \%$ (vol/vol) to remove the soluble matter contained in each sample. The silt fraction was determined by sedimentation using particle size analysis. Most biogenic silica in soils is associated to the silt fraction. Glass microscope slide containing of this fraction were mounted on an immersion oil type A for silica body identification. The results showed a variety of forms and abundance of silica bodies in the studied soils. The variation in form and abundance was highest in the soil formed from quartzite. No differences in abundance of phytoliths were observed in the Oxisols from the Cerrado, Mata Atlântica and Caatinga biomes.
\end{abstract}

Index terms: phytoliths, opal, biogenic silica, silica.

\section{INTRODUÇÃO}

Corpos silicosos ou opala biogênica são terminologias usadas para designar compostos de sílica hidratada $\left(\mathrm{SiO}_{2} \cdot \mathrm{nH}_{2} \mathrm{O}\right)$, com formas e tamanhos característicos, formados pelas plantas (Piperno, 2006) e animais (Garrone et al., 1981). Nesse conceito são contemplados os fitólitos, frústulas e espículas.

Fitólitos são corpos silicosos microscópicos amorfos aos raios $\mathrm{X}$, que resultam de processos nos quais determinadas plantas superiores depositam sílica intra e extracelular após absorvê-la da solução do solo (Jones, 1964; Kondo \& Sase, 1986; Costa et al., 2005). As principais acumuladoras de Si e produtoras de fitólitos são as Poaceae, mas outras famílias de monocotiledôneas e algumas dicotiledôneas também acumulam quantidades expressivas de sílica (Runge, 1999).

As deposições de sílica biogênica nos vegetais podem ocorrer em folhas, sementes, frutos, raízes e madeira, dentro das células ou na parede celular (Sendulsky \& Labouriau, 1966; Runge, 1999), e algumas morfologias de fitólitos são únicas, sendo assim utilizados na identificação das plantas produtoras no nível de família e às vezes de gênero (Parry \& Smithson, 1964; Sendulsky \& Labouriau, 1966; Campos \& Labouriau, 1969; Silva \& Labouriau, 1970; Piperno, 2006; Calegari, 2008), possibilitando o uso de fitólitos de solos e sedimentos na reconstituição de paleovegetações e paleoclimas (Runge, 1999).

As algas, especialmente as diatomáceas, e esponjas também produzem corpos silicosos, recebendo estes as denominações de frústulas e espículas, respectivamente. Nas diatomáceas, as paredes celulares, denominadas frústulas, são compostas de opala-A, e esses organismos são os principais produtores de sílica biogênica, tanto em quantidade de material sintetizado quanto na variedade de estruturas (Hildebrand, 2003). Já as esponjas são de dois tipos: calcárias e silicosas; estas últimas absorvem o Si como componente de seu esqueleto, que é formado por espículas, as quais servem para fixá-las ao leito oceânico, fluvial ou lacustre (Coradin et al., 2004).

Seja qual for a origem da sílica biogênica, formada em plantas ou animais, o depósito junto às paredes celulares geralmente replica a morfologia das células vivas (Parr \& Sullivan, 2005); assim, as formas e ornamentações da sílica biogênica são taxonomicamente únicas, possibilitando o uso de corpos silicosos de solos e sedimentos em interpretações paleoecológicas (RuizMoreno \& Carreño, 1994; Runge, 1999; Yim \& Li, 2000).

Além disso, os corpos silicosos podem ser usados para determinação da idade de camadas de sedimentos ou horizontes de solos, já que o C ocluso neles é preservado por muito tempo, especialmente em ambiente redutor. Parr \& Sullivan (2005) observaram acúmulo de 0,72 a $0,88 \mathrm{~g} \mathrm{~m}^{-2} \mathrm{ano}^{-1} \mathrm{de} \mathrm{C}$ na forma de C ocluso em fitólitos sob vegetação natural em dois locais na Oceania.

Os estudos de corpos silicosos concentram-se nas áreas de Botânica, Arqueologia, Paleontologia, Geologia, Ecologia, Agricultura, Microscopia, Antropologia e Geoquímica. Na Ciência do Solo o Si tem sido estudado pelo seu papel na sustentação de plantas, especialmente as monocotiledôneas (Agarie et al., 1996), na proteção adicional ao ataque de herbívoros (artrópodes ou outros) e patógenos (fungos e bactérias) (Jones \& Handreck, 1967; Epstein 1999) e como fertilizante no aumento da produção de matéria seca e produtividade de grãos (Korndörfer et al., 1999; Barbosa Filho et al., 2001; Mauad et al, 2003). No Brasil, tem havido omissão quanto às investigações referentes à identificação de corpos silicosos em solos e sedimentos para fins de interpretação da gênese do solo, bem como do papel das plantas no aporte 
constante de sílica biogênica (Lucas et al., 1993, 2001; Alexandre et al., 1997; Carnelli et al., 2002; Calegari, 2008), para que o equilíbrio químico na solução do solo mantenha os teores de sílica suficientes para a manutenção de minerais silicatados.

Dada a importância do Si na crosta terrestre e nas diversas formas de vida, ainda há pouco saber acumulado sobre o tema e muito a ser pesquisado sobre os processos de gênese e taxonomia dos corpos silicosos nas paisagens do Brasil e do mundo. O primeiro registro sobre o estudo de corpos silicosos no Brasil data de 1957 e foi publicado por Fontana Jr. \& Muth, do Instituto Oswaldo Cruz. Os autores estudaram a morfologia e a estrutura de corpos silicosos nas diferentes partes da planta de Panicum maximum e as denominaram de sílico-esqueleto, fazendo uma analogia ao observado em diatomáceas. Devem-se destacar também esforços como os de Sendulsky \& Laboriau (1966); Campos \& Laboriau (1969) e Silva \& Laboriau (1970), em estudos de corpos silicosos em diferentes espécies vegetais do Cerrado brasileiro. Apesar de terem se passado 52 anos desde a primeira publicação sobre o assunto, o número de publicação brasileira na temática ainda é baixo.

Diante do exposto, a presente pesquisa objetivou identificar a ocorrência de corpos silicosos encontrados em horizontes superficiais de solos oriundos de diferentes ecossistemas terrestres, para fins de interpretação dos possíveis fatores ambientais responsáveis pela sua gênese.

\section{MATERIAL E MÉTODOS}

\section{Solos e áreas de estudo}

Foram coletadas amostras do horizonte superficial de 10 perfis de solos pertencentes às classes: Criossolo, Organossolo, Cambissolo, Latossolo e Vertissolo, situados em áreas e regiões distintas do Brasil (Quadro 1); eles foram escolhidos com base no Sistema Brasileiro de Classificação de Solos (Embrapa, 2006),

Quadro 1. Descrição dos pedossistemas onde se inserem os perfis amostrados

\begin{tabular}{|c|c|c|c|c|c|c|c|}
\hline $\begin{array}{l}\text { Horizonte } \\
\text { (Prof.) }\end{array}$ & Localização & $\begin{array}{l}\text { Coordenadas } \\
\text { geográficas }\end{array}$ & Altitude & Material de origem & $\begin{array}{l}\text { emperatura } \\
\text { média }\end{array}$ & Precipitação & Vegetação \\
\hline \multirow[t]{2}{*}{$\mathrm{cm}$} & & & $\mathrm{m}$ & & ${ }^{\circ} \mathrm{C}$ & $\mathrm{mm}$ ano ${ }^{-1}$ & \\
\hline & \multicolumn{7}{|c|}{ Perfil 1 - Criossolo Ornitogênico Alofânico ${ }^{(1)}$} \\
\hline \multirow[t]{2}{*}{$\mathrm{H}(0-70)$} & $\begin{array}{l}\text { Baía do Almirantado, } \\
\text { Continente Antártico }\end{array}$ & $\begin{array}{l}62^{\circ} 05^{\prime} 07^{\prime \prime} \mathrm{S} \mathrm{e} \\
58^{\circ} 23^{\prime} 33^{\prime \prime} \mathrm{W}\end{array}$ & 69 & $\begin{array}{l}\text { Diques vulcânicos, com } \\
\text { composições variando de } \\
\text { basaltos a andesitos }\end{array}$ & $-1,8$ & 360 & Musgos e liquens \\
\hline & \multicolumn{7}{|c|}{ Perfil 2 - Organossolo Mésico Sáprico típico ${ }^{(2)}$} \\
\hline \multirow[t]{2}{*}{$\mathrm{O}(0-44)$} & $\begin{array}{l}\text { Serra Verde, Bocaína de } \\
\text { Minas, Mantiqueira, MG }\end{array}$ & $\begin{array}{l}22^{\circ} 10^{\prime} 00^{\prime \prime} \mathrm{S} \mathrm{e} \\
44^{\circ} 34^{\prime} 00^{\prime \prime} \mathrm{W}\end{array}$ & 1.700 & $\begin{array}{l}\text { Gnaisses e migmatitos com } \\
\text { veios de anfibolito e quartzo }\end{array}$ & 16,7 & 1.500 & $\begin{array}{l}\text { Floresta Ombrófila } \\
\text { Densa Montana e }\end{array}$ \\
\hline & \multicolumn{6}{|c|}{ Perfil 3 - Organossolo Fólico Tb distrófico ${ }^{(3)}$} & \\
\hline \multirow[t]{2}{*}{$\mathrm{O}(0-30)$} & Ilha de Trindade, ES & $\begin{array}{l}20^{\circ} 51^{\prime} 24,1^{\prime \prime} \mathrm{S} \mathrm{e} \\
29^{\circ} 32^{\prime} 55,0^{\prime \prime} \mathrm{W}\end{array}$ & 554 & $\begin{array}{l}\text { Lavas e intrusões sódico - } \\
\text { alcalinas }\end{array}$ & 25,2 & 900 & $\begin{array}{l}\text { Floresta nebular/ } \\
\text { transicional para }\end{array}$ \\
\hline & \multicolumn{6}{|c|}{ Perfil 4 - Cambissolo Háplico Ta Eutrófico léptico ${ }^{(2)}$} & campo rupestre \\
\hline \multirow[t]{2}{*}{$\mathrm{A}(0-30)$} & Patrocínio, MG & $\begin{array}{l}18^{\circ} 41^{\prime} \mathrm{S} \mathrm{e} \\
44^{\circ} 01^{\prime} \mathrm{W}\end{array}$ & 1.000 & Ígneas ultrabásicas - dunito & 21,6 & 1.643 & $\begin{array}{l}\text { Floresta } \\
\text { subperenifólia }\end{array}$ \\
\hline & \multicolumn{7}{|c|}{ Perfil 5 - Latossolo Amarelo A húmico ${ }^{(4)}$} \\
\hline \multirow[t]{2}{*}{$\mathrm{A}(0-30)$} & Crato, CE & $\begin{array}{l}7^{\circ} 13^{\prime} \mathrm{S} \text { e } \\
39^{\circ} 19^{\prime} \mathrm{W}\end{array}$ & 870 & Arenitos & 26 & 700 & $\begin{array}{l}\text { Floresta } \\
\text { subperenifólia }\end{array}$ \\
\hline & \multicolumn{7}{|c|}{ Perfil 6 - Latossolo Amarelo A proeminente ${ }^{(2)}$} \\
\hline \multirow[t]{2}{*}{$\mathrm{A}(0-30)$} & Berilo, MG & - & $>800$ & $\begin{array}{l}\text { Sedimentos argilosos do } \\
\text { Terciário }\end{array}$ & 24 & 900 & $\begin{array}{l}\text { Cerrado tropical } \\
\text { subcaducifólio }\end{array}$ \\
\hline & \multicolumn{7}{|c|}{ Perfil 7 - Latossolo Vermelho-Amarelo A húmico ${ }^{(2)}$} \\
\hline \multirow[t]{2}{*}{$\mathrm{A}(0-30)$} & Caratinga, MG & $\begin{array}{l}19^{\circ} 37^{\prime} 30^{\prime \prime} \mathrm{S} \\
42^{\circ} 09^{\prime} 00^{\prime \prime} \mathrm{W}\end{array}$ & 1.100 & $\begin{array}{l}\text { Charnockitos, granulitos, } \\
\text { dioritos e gabros }\end{array}$ & 22,7 & 1.200 & $\begin{array}{l}\text { Floresta tropical } \\
\text { perenifólia }\end{array}$ \\
\hline & \multicolumn{7}{|c|}{ Perfil 8 - Latossolo Amarelo A proeminente ${ }^{(5)}$} \\
\hline \multirow[t]{2}{*}{$\mathrm{A}(0-30)$} & Garanhuns, PE & $\begin{array}{l}9^{\circ} 00^{\prime} \quad 00^{\prime \prime} \mathrm{S} \\
36^{\circ} 00^{\prime} 00^{\prime \prime} \mathrm{W}\end{array}$ & 860 & $\begin{array}{l}\text { Sedimentos arenosos } \\
\text { do Terciário }\end{array}$ & 29,4 & 800 & $\begin{array}{l}\text { Remanescentes } \\
\text { de floresta }\end{array}$ \\
\hline & \multicolumn{7}{|c|}{ Perfil 9 - Vertissolo A moderado e textura argilosa ${ }^{(5)}$} \\
\hline \multirow[t]{2}{*}{$\mathrm{A}(0-30)$} & Cachoeirinha, PE & $\begin{array}{l}8^{\circ} 30^{\prime} 00^{\prime \prime} \mathrm{S} \mathrm{e} \\
36^{\circ} 30^{\prime} 00^{\prime \prime} \mathrm{W}\end{array}$ & 520 & $\begin{array}{l}\text { Calcário com } \\
\text { flogopita-diopsídio- } \\
\text { actnolita }\end{array}$ & 21 & $\begin{array}{l}800 \\
a \\
900\end{array}$ & $\begin{array}{l}\text { Caatinga } \\
\text { hipoxerófila } \\
\text { arbustiva e campos }\end{array}$ \\
\hline & \multicolumn{7}{|c|}{ Perfil 10 - Cambissolo Húmico distrófico latossólico ${ }^{(2)}$} \\
\hline $\mathrm{O}(0-20)$ & Ibitipoca, MG & $\begin{array}{l}21^{\circ} 40^{\prime} 00^{\prime \prime} \mathrm{S} \mathrm{e} \\
43^{\circ} 55^{\prime} 00^{\prime \prime} \mathrm{W}\end{array}$ & $\begin{array}{l}1.050- \\
1.784\end{array}$ & $\begin{array}{l}\text { Quartzitos sacaroidais } \\
\text { grosseiros, Quartzitos } \\
\text { finos micáceos e } \\
\text { biotita xistos }\end{array}$ & 18,9 & 1.380 & $\begin{array}{l}\text { Complexo rupestre } \\
\text { de altitude }\end{array}$ \\
\hline
\end{tabular}

${ }^{(1)}$ Setzer et al., 2004. ${ }^{(2)}$ Radambrasil, 1983a. ${ }^{(3)}$ Almeida, 1961. ${ }^{(4)}$ Radambrasil, 1981. ${ }^{(5)}$ Radambrasil, $1983 b$. 
com exceção apenas do Criossolo Ornitogênico (continente antártico), classificado pelo Sistema Internacional de Classificação de Solos elaborado pela FAO (ISSS Working Group WRB, 2006). Procurouse obter ampla variedade quanto ao material de origem e clima dos solos, com a finalidade de selecionar solos distintos.

O estudo envolveu solos orgânicos e minerais oriundos de ambientes contrastantes quanto ao material orgânico aportado, produto de diferentes rotas de humificação. São, portanto, solos diferenciados em atributos pedoclimáticos, e essas diferenças justificam estudos de corpos silicosos em solos.

\section{Extração dos corpos silicosos no solo}

$\mathrm{O}$ método adotado na presente pesquisa para extração dos corpos silicosos foi modificado de Costa (2004). Inicialmente, as amostras coletadas são secas em temperatura ambiente para obtenção da terra fina, por peneiramento. Após esse procedimento, $5 \mathrm{~g}$ de solo foram acondicionados em cadinho de porcelana $\mathrm{e}$ permaneceram na mufla a $500{ }^{\circ} \mathrm{C}$ por $5 \mathrm{~h}$, para remoção da matéria orgânica. $\mathrm{O}$ material então foi tratado com $\mathrm{HCl} 10 \mathrm{cL} \mathrm{L}^{-1}$, durante $1 \mathrm{~h}$, para eliminação das impurezas contidas nas cinzas (relação 1:2,5 - cinza:solução). Em seguida, centrifugou-se a $1.300 \mathrm{~g}$ por $5 \mathrm{~min}$. Essa etapa foi repetida mais duas vezes com $\mathrm{HCl}\left(10 \mathrm{cL} \mathrm{L}^{-1}\right)$ e duas lavagens com $\mathrm{H}_{2} \mathrm{O}$ destilada. Em cada uma dessas etapas o sobrenadante foi descartado.

Após o procedimento descrito, removeu-se a fração areia, passando as amostras de solo em peneira de malha entre 0,053 a $2,000 \mathrm{~mm}$. A fração silte foi separada da argila por sedimentação e a remoção desta foi feita por sinfonamento, a partir de 10 agitações a cada 10 min, com descarte do sobrenadante. O silte foi seco em estufa com ventilação forçada a $105-110^{\circ} \mathrm{C}$.

A identificação dos corpos silicosos foi realizada em lâminas com amostras de silte, utilizando óleo de imersão para facilitar a visualização em microscópio óptico Olympus CX31 (com aumentos de 100 e 400 vezes). Foram escolhidos cinco campos para observação e contagem dos corpos silicosos em cada amostra de solo.

Para identificação dos tipos morfológicos dos fitólitos, há várias terminologias que se baseiam nos contornos dos corpos de opala-A e em suas dimensões (Twiss et al., 1969; Twiss, 1992; Fredlund \&Tieszen, 1994; Lu \& Liu, 2003). No entanto, na presente pesquisa foi usada, para identificação de tipos morfológicos dos fitólitos do material coletado, a terminologia mais nova elaborada por Madella et al. (2005).

A identificação das frústulas de diatomáceas foi feita com base no trabalho de Moreira (1975), e a das espículas, segundo Costa et al. (1992).

\section{RESULTADOS E DISCUSSÃO}

Os resultados revelaram variedade de formas e de abundância de corpos silicosos nos horizontes superficiais dos solos dos diferentes ecossistemas estudados (Quadro 2); os principais fitólitos identificados foram bastonetes de tamanhos variados, buliforme, sela, halteres e formas retangulares, sendo bastonete e buliforme os mais abundantes e comuns a todos os ecossistemas (Quadro 2 e Figura 1). Segundo Runge (1999), esses morfotipos têm significado taxonômico com a família Poaceae, de ampla distribuição geográfica nos diversos ecossistemas, sendo uma das que mais acumulam $\mathrm{Si}$ e produzem fitólitos.

A maior variedade e maior abundância de corpos silicosos foram registradas na fração silte do Cambissolo Húmico distrófico latossólico, localizado no Parque Estadual do Ibitipoca-MG (Quadro 2). Com cotas altimétricas que variam de 1.050 a $1.784 \mathrm{~m}$ (Quadro 1), a Serra do Ibitipoca é localmente dominada por uma geologia de quartzitos sacaroidais grosseiros com muscovita, intercalações de quartzitos finos micáceos e biotita - xistos, pertencentes ao grupo Andrelândia (Dias, 2000).

Além da riqueza em quartzo no material de origem do solo, a formação e permanência dos corpos silicosos nesse ecossistema deve-se ao tipo de vegetação, Complexo Rupestre de Altitude, que demanda altos teores de sílica da solução do solo para sua constituição vegetal. Assim, a presença desse tipo de vegetação na área indica que a mineralogia está sendo eficiente em manter concentrações adequadas de Si na solução do solo, protegendo os corpos silicosos da dissolução. Segundo Pereira (1994), o Complexo Rupestre de Altitude sobre quartzito na Serra de Ibitipoca está associado à Floresta Estacional Semidecidual, onde são observadas espécies herbáceas de aspecto graminoide crescendo sobre solo arenopedregoso, com elevado número de indivíduos pertencentes às famílias Poaceae, Cyperaceae e Eriocaulaceae. As plantas das famílias das monocotiledôneas são as principais acumuladoras de Si e produtoras de fitólitos (Runge, 1999), e para essas famílias a absorção de silica é proporcional à concentração de ácido monossilícico na solução do solo (Jones \& Handreck, 1965; Fox et al., 1967; Jones \& Handreck, 1967). As poáceas e ciperáceas estão entre as monocotiledôneas que mais acumulam $\mathrm{Si}$ (Hodson et al., 2005).

Os solos dos ecossistemas da Antártica e da Ilha de Trindade apresentaram abundância mediana em corpos silicosos, e os de Serra Verde (MG) e Garanhuns (PE), pouca abundância, sendo o fitólito do tipo bastonete comum a todos esses ecossistemas (Quadro 2).

Destaca-se a pobreza em sílica biogênica dos Latossolos, cuja abundância variou de pouca a rara em Vertissolo nordestino sob remanescente de floresta subperenifólia e Caatinga hipoxerófila arbustiva e 
Quadro 2. Registro das ocorrências de corpos silicosos da fração silte em horizontes superficiais de solos provenientes de diferentes ecossistemas

\begin{tabular}{|c|c|c|c|c|}
\hline Identificado & Abundância ${ }^{(1)}$ & Morfotipo & Vegetação & Local \\
\hline 6 & 3 & $\begin{array}{l}\text { Tecido silicificado, buliforme, } \\
\text { bastonete, diatomácea } \\
\text { elíptica, halteres, sela. }\end{array}$ & Musgos e Liquens & Antártica \\
\hline 4 & 2 & $\begin{array}{l}\text { Bastonete, buliforme, halteres, } \\
\text { pedaço de espícula de esponja. }\end{array}$ & $\begin{array}{l}\text { Floresta Ombrófila densa } \\
\text { Montana }\end{array}$ & Serra Verde - MG \\
\hline 5 & 3 & $\begin{array}{l}\text { Diatomácea retangular, } \\
\text { bastonete serrilhado, corpo } \\
\text { silicoso perfurado castanho, } \\
\text { sela mal formada, pólen. }\end{array}$ & $\begin{array}{l}\text { Floresta Nebular/transicional } \\
\text { para Campo Rupestre com } \\
\text { estande uniforme de } \\
\text { Cyatheae delgadii }\end{array}$ & Ilha de Trindade \\
\hline 2 & 1 & Célula buliforme, bastonete & Floresta Subperenifólia & Patrocínio, MG \\
\hline 2 & 1 & Bastonete, bastonete corroído & Floresta Subperenifólia & Crato - CE \\
\hline 2 & 1 & Bastonetes & Cerrado Tropical Subcaducifólio & Berilo - MG \\
\hline 2 & 1 & Bastonete corroído, sela & Floresta Tropical Perenifólia & Caratinga - MG \\
\hline 4 & 2 & $\begin{array}{l}\text { Forma não identificada, Cruz, } \\
\text { bastonete, forma retangular }\end{array}$ & $\begin{array}{l}\text { Remanescentes de Floresta } \\
\text { Subperenifólia }\end{array}$ & Garanhuns - PE \\
\hline 2 & 1 & Bastonete, halteres & $\begin{array}{l}\text { Caatinga Hipoxerófila Arbustiva } \\
\text { e Campos antrópicos }\end{array}$ & Cachoeirinha - PE \\
\hline 9 & 5 & $\begin{array}{l}\text { Bastonete de tamanhos } \\
\text { variados, buliforme, sela, } \\
\text { halteres, formas retangulares, } \\
\text { outras formas, pedaço de } \\
\text { espícula de esponja, }\end{array}$ & Complexo Rupestre de altitude & Ibitipoca - MG \\
\hline
\end{tabular}

(1) O termo abundância refere-se à regularidade com que as formas aparecem nos campos e nas lâminas observadas, em que 1: rara, 2: pouca, 3: mediana, 4: alta e 5: muito alta.

campos antrópicos (Cachoeirinha e Crato), conforme pode ser visualizado no quadro 2. Nesse particular, Ramírez et al. (2007) confirmam que os altos níveis de evapotranspiração em ambiente quente e úmido favorecem a precipitação do ácido monossilícico na forma de um gel, sílica amorfa, na epiderme foliar, no lugar de fitólitos. Para os ambientes mais secos, a absorção do ácido monossilícico seria irrelevante, pois somente uma pequena concentração de sílica estaria disponível para a planta.

Nos Latossolos de Caratinga (MG) e do Crato (PE) registrou-se a presença de fitólitos do tipo bastonete com aspecto de corrosão (Quadro 2). Runge (1999) observou que solos de regiões tropicais apresentavam fitólitos nas suas partes mais profundas, com considerável corrosão, e atribuiu esse aspecto à idade.

Quanto à influência dos atributos químicos dos solos na maior ou menor abundância dos corpos silicosos encontrados nos diferentes ecossistemas estudados nesta pesquisa, Drees et al. (1989) reportam valores de solubilidade da opala biogênica variando de 0,5 a $10 \mathrm{mg} \mathrm{L}^{-1} \mathrm{Si}\left(1,07\right.$ a $\left.21,4 \mathrm{mg} \mathrm{L}^{-1} \mathrm{SiO}_{2}\right)$ e sugerem que a presença de $\mathrm{Fe}$ e $\mathrm{Al}$ adsorvidos, assim como de $\mathrm{C}$ ocluso, pode alterar os valores de solubilidade da sílica. Wilding \& Drees (1974), citados por Drees et al. (1989), observaram que corpos de opala de coloração amarronzada a opaca eram menos solúveis do que corpos quase transparentes, ambos originários de um paleossolo da Malásia, sugerindo que compostos orgânicos são responsáveis pela coloração escura, de alguma forma, retardavam a dissolução da sílica.

Os teores de C orgânico total (COT) variaram de 0,9 a 30 dag kg-1 nos solos estudados (Quadro 3); alguns valores excepcionalmente altos foram encontrados nas amostras de Organossolos (12,14 e 23,15 dag kg-1) de Serra Verde e Ilha de Trindade, respectivamente, e de Cambissolo (30 dag $\left.\mathrm{kg}^{-1}\right)$ de Ibitipoca.

No solo Antártico, os conteúdos de COT são preservados nas condições de frio intenso. A natureza fíbrica do material, associada à pequena contribuição da fauna do solo na fragmentação da matéria orgânica leve, leva à preservação desse material por longos períodos. Outro importante fator de conservação desse material pode estar ligado à natureza amorfa da fração mineral, que adsorve o material orgânico, conferindolhe proteção física. Esses minerais oferecem inúmeros sítios de adsorção para exercer ação protetora contra a degradação biótica, adsorvendo e consequentemente reduzindo a atividade de importantes agentes da decomposição, como amilases e proteases (Michel, 2005). 


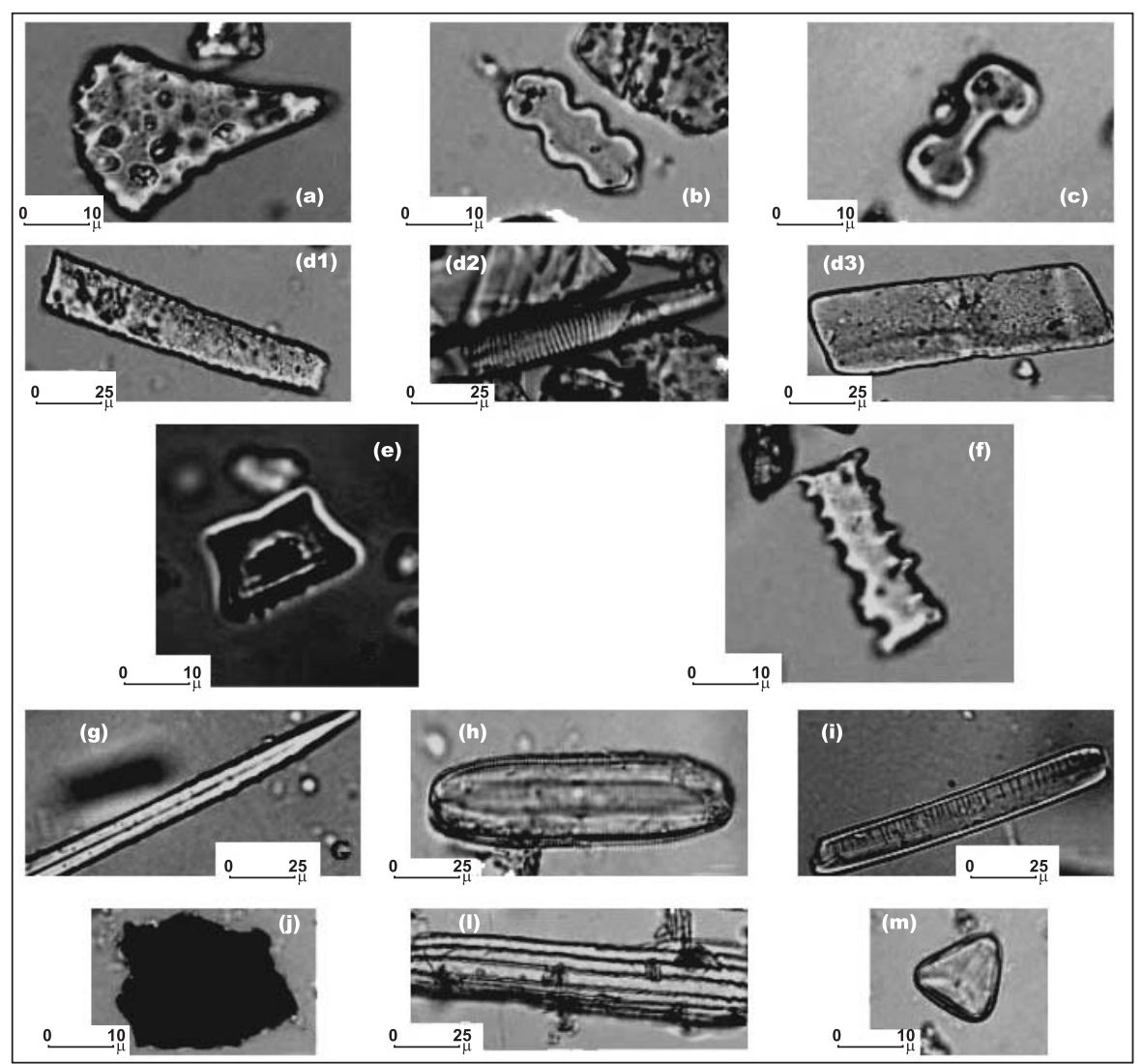

Figura 1. Fotomicrografias de morfotipos de corpos silicosos (fitólitos, espículas de esponjas e diatomáceas) encontrados na fração silte em horizontes superficiais de solos de diferentes ecossistemas: Fitólitos: (a) buliforme; (b) trilobado; (c) halter; (d1, 2 e 3) bastonetes; (e) sela ou rondele; (f) bastonete serrilhado; (g) espícula de esponja; (h) diatomácea elíptica; (i) diatomácea retangular; (j) corpo silicoso perfurado; (l) tecido silificado; (m) grão de pólen.

Quadro 3. Solo, profundidade de coleta, carbono orgânico total e pH do solo nos diferentes pedoambientes]

\begin{tabular}{llccc}
\hline \multicolumn{1}{c}{ Local } & Classe de solo & Profundidade & COT YB & pH do solo $\mathbf{H}_{2} \mathbf{O}$ \\
\hline & & $\mathrm{cm}$ & dag kg & \\
Antártica & Criossolo & $0-70$ & 3,24 & 4,48 \\
Serra Verde - MG & Organossolo & $0-44$ & 12,14 & 4,96 \\
Ilha de Trindade & Organossolo & $0-30$ & 23,15 & 4,00 \\
Patrocínio - MG & Cambissolo & $0-30$ & 2,50 & 7,20 \\
Crato - CE & Latossolo & $0-30$ & 2,21 & 4,80 \\
Berilo - MG & Latossolo & $0-30$ & 2,60 & 4,96 \\
Caratinga - MG & Latossolo & $0-30$ & 4,52 & 5,61 \\
Garanhuns - PE & Latossolo & $0-30$ & 0,90 & 7,30 \\
Cachoeirinha - PE & Vertissolo & $0-30$ & 1,00 & 4,21 \\
Ibitipoca - MG & Cambissolo & $0-20$ & 30,00 & \\
\hline
\end{tabular}

(1) COT (Carbono Orgânico Total) por YB: Yeomans \& Bremner (1988).

O Organossolo de Trindade encontra-se numa condição de maior umidade e acúmulo de matéria orgânica na liteira, cujo material ainda se encontra inalterado, sendo proveniente de restos orgânicos da floresta de Cyathea delgadii e Myrsine floribunda. Os elevados teores de COT sugerem que as condições ambientais não são favoráveis à decomposição da matéria orgânica, sobretudo pela ausência de detritívoros e herbívoros. Assim, para o Organossolo da Ilha de Trindade a manutenção dos corpos silicosos no solo parece ser influenciada pela presença de altos teores em compostos orgânicos, aliada ao tipo de vegetação. 
Com relação à influência do $\mathrm{pH}$ na estabilidade e dissolução de corpos silicosos, Fraysse et al. (2006) encontraram, para os fitólitos de bambu coletados na Ilha Réunion, solubilidade próxima à da sílica amorfa, e a velocidade de dissolução ficou entre aquelas do quartzo e da sílica vítrea, mostrando-se similarmente dependente do $\mathrm{pH}$, chegando a um mínimo de velocidade de dissolução em pH 3,0. Strömberg (2004) afirma que nas condições de $\mathrm{pH}$ encontradas geralmente nos solos, entre 4,0 e 8,0, os fitólitos neles permanecem por longos períodos de tempo.

Os valores de $\mathrm{pH}$ em água (Quadro 3) evidenciam que os solos amostrados apresentam valores entre 4,0 e 7,3, estando portanto dentro da faixa citada por Strömberg (2004), favorecendo assim a estabilidade e manutenção dos corpos silicosos nos ecossistemas estudados. Outros fatores, como alto índice pluviométrico, temperatura elevada e atividade microbiana, são também decisivos na ciclagem da sílica biogênica e, consequentemente, no aporte de ácido monossilícico na solução do solo (Street-Perrott $\&$ Barker, 2008).

Além de fitólitos, identificou-se a ocorrência de diatomáceas e espículas de esponjas, porém estas apenas em condições ambientais peculiares, como na Antártica, na Ilha de Trindade, em Serra Verde e em Ibitipoca (Quadro 2 e Figura 1). A presença desses tipos de corpos silicosos em solos pode estar associada às condições ambientais onde esses solos se formaram. $\mathrm{Na}$ Antártica e na Ilha de Trindade a influência marinha justifica a ocorrência de diatomáceas, e nos solos de Serra Verde e Ibitipoca, ambos de regiões Altimontana da Mantiqueira, a presença de espícula de esponja indica que os solos foram formados em ambiente de drenagem imperfeita, conforme constatado por Costa et al. (1992) em solos de João Pinheiro - MG.

O Organossolo de Serra Verde e o Cambissolo Húmico de Ibitipoca amostrados são representativos de áreas coluvionares de pés de encostas e formaramse em ambiente de recepção, com maior tempo de permanência de água, ratificando assim que as condições ambientais foram propícias para a ocorrência de espícula de esponja, corroborando as conclusões de Costa et al. (1992).

\section{CONCLUSÕES}

1. Há uma natural diversidade de morfotipos e abundância de fitólitos nos solos estudados: bastonetes de tamanhos variados, buliforme, sela, halteres e formas retangulares, sendo bastonete e buliforme as formas mais abundantes.

2. A corrosão, observada em todas as formas, foi maior nos buliformes, seguidos dos bastonetes.

3. Os corpos silicosos foram bem mais abundantes e diversificados no único solo desenvolvido de quartzito.
4. Não houve diferenças de abundância de fitólitos entre os Latossolos sob Cerrado, Mata Atlântica e Caatinga.

\section{LITERATURA CITADA}

AGARIE, S.; AGATA, W.; UCHIDA, H.; KUBOTA, F. \& KAUFMAN, P.B. Function of silica bodies in the epidermal system of rice (Oryza sativa L.): Testing the window hypothesis. J. Exper. Bot., 47:655-660, 1996.

ALEXANDRE, A.; MEUNIER, J.D.; COLIN, F. \& KOUD, J.M. Plant impact on the biogeochemical cycle of silicon and related weathering processes. Geochim. Cosmochim. Acta, 61:677-682, 1997.

ALMEIDA, F.F.M. Geologia e Petrologia na Ilha de Trindade. Rio de Janeiro, DNPM/DGM, 197p. 1961. (Monografia)

BARBOSA FILHO, M.P.; SNYDER, G.H.; FAGERIA, N.K.; DATNOFF, L.E. \& SILVA, O.F. Silicato de cálcio como fonte de silício para o arroz de sequeiro. R. Bras. Ci. Solo, 25:325-30, 2001.

CALEGARI, M.R. Ocorrência e significado paleoambiental do horizonte A húmico em Latossolos. Piracicaba, Escola Superior de Agricultura Luiz de Queiroz, 2008. 259p. (Tese de Doutorado)

CAMPOS, A.C. \& LABOURIAU, L.G. Corpos silicosos de gramíneas dos Cerrados - II. Pesq. Agropec. Bras., 4:143151, 1969.

CARNELLI, A.L.; MADELLA, M.; THEURILLAT, J.P. \& AMMANN, B. Aluminum in the opal silica reticule of phytoliths: A new tool in palaeoecological studies. Am. J. Bot., 89:346-351, 2002

CORADIN, T.; LOPEZ, P.J.; GAUTIER, C. \& LIVAGE, J. From biogenic to biomimetic silica. Comptes Rendus Palevol., 3:443-452, 2004.

COSTA, L.M. Biogeoquímica do silício: Morfologia e composição química de fitólitos relacionados a solos ácidos com alta saturação em alumínio trocável. 2004. 23p (Relatório Final de Estágio Pós-Doutorado)

COSTA, L.M.; GUEDES, I.M.R.; MORRIS, L.A.; WEST, L. \& OLIVEIRA, A.P. Biogeochemistry of silica phytoliths in agriculture. In: SILICON IN AGRICULTURE CONFERENCE, 3., Uberlândia, 2005. Proceedings... Uberlândia, Universidade Federal de Uberlândia, 2005. p.23-25.

COSTA, L.M.; KELLER, W.D. \& JOHNS, W.D. Espículas de esponja em solos de João Pinheiro, Minas Gerais. R. Ceres, 39:597-603, 1992 .

DIAS, H.T. Caracterização de pedoambientes no Parque Estadual do Ibitipoca. Viçosa, MG, Universidade Federal de Viçosa, 2000. 121p. (Tese de Doutorado)

DREES, L.R.; WILDING, L.P.; SMECK, N.E. \& SENKAYI, A.L. Silica in soils: Quartz and disordered silica polymorphs. In: DIXON J.B. \& WEED, S.B., eds. Minerals in soil environments. 2.ed. Madison, Soil Science Society of America, 1989. (SSSA Book Series, 1) 
EMPRESA BRASILEIRA DE PESQUISA AGROPECUÁRIA . EMBRAPA. Centro Nacional de Pesquisa de Solos. Sistema brasileiro de classificação de solos. 2.ed. Rio de Janeiro, Embrapa Solos, 2006. 306p.

EPStEIN, E. Silicon. Ann. Rev. Plant Physiol. Plant Molec. Biol., 50:641-644, 1999.

FONTANA JR., P. \& MUTH, H. Estruturas silicosas na gramínea Panicum maximum. Memórias do Instituto Oswaldo Cruz, 5:135-144, 1957.

FOX, R.L.; SILVA, J.A.; YOUNGE, O.R.; PLUCKNETT, D.L. \& SHERMAN, G.D. Soil and plant silicon and silicate response by sugar cane. Proc. Soil Sci. Soc. Am., 31:775$779,1967$.

FRAYSSE, F.; POKROVSKY, O.S.; SCHOTT, J. \& MEUNIER, J.D. Surface properties, solubility and dissolution kinetics of phytoliths from bamboos of Reunion Island. Geochim. Cosmochim. Acta Suppl., A216, 2004. (Proc. 14 ${ }^{\text {th }}$ Ann. Goldschmidt Conf.)

FREDLUND, G.G. \& TIESZEN, L.L. Modern phytolith assemblages from the North American Great Plains. J. Biogeogr., 21:321-335, 1994.

GARRONE, R.; SIMPSON, T.L. \& POTTU-BOUMENDIL, J. Ultrastruture and deposition of silica in sponges. In: SIMPSON, T.L. \& VOLCANI, B.E., eds. Silicon and siliceous structure in biological systems. New York, Springer-Verlag, 1981. p.453-493.

HILDEBRAND, M. Biological processing of nanostructured silica in diatoms. Progress Organic Coatings, 47:256-266, 2003.

HODSON, M.J.; WHITE, P.J.; MEAD, A. \& BROADLEY, M.R. Phylogenetic variation in the silicon composition in plants. Ann. Bot., 96:1027-1046, 2005.

ISSS WORKING GROUP WRB. 2006. World Reference Base for Soil Resources. World Soil Resources Report, № 103, FAO, Rome.

JONES, R.L. Note on occurrence of opal phytoliths in some Cenozoic sedimentary rocks. J. Paleont., 38:773-775, 1964.

JONES, L.H.P. \& HANDRECK, K.A. Studies of silica in the oat plants. III - Uptake of silica from soils by the plant. Plant Soil, 23:79-96, 1965.

JONES, L.H.P. \& HANDRECK, K.A. Silica in soils, plants and animals. Adv. Agron. 19:107-149, 1967.

KONDO, R. \& SASE, T. Opal phytoliths, their nature and application. Quarter. Res., 25:31-63, 1986.

KORNDÖRFER, G.H.; ARANTES, V.A.; CORRÊA, G.F. \& SNYDER, G.H. Efeito do silicato de cálcio no teor de silício e na produção de grãos de arroz de sequeiro. R. Bras. Ci. Solo, 23:635-41, 1999.

LUCAS, Y. The role of plants in controlling rates and products of weathering: Importance of biological pumping. Ann. Rev. Earth Planet. Sci., 29:135-163, 2001.
LUCAS, Y.; LUIZAO, F.J.; ROUILLER, J. \& NAHON, D. The relationship between the biological activity of the rain forest and the mineral composition of the soils. Science, 260:521-523, 1993.

LU, H. \& LIU, K. Phytoliths of common grasses in the coastal environments of southeastern USA. Estuarine Coastal Shelf Sci., 58:587-600, 2003.

MADELLA, M.; ALEXANDRE, M. \& BALL, T. International code for phytolith nomenclature 1.0. Ann. Bot., 96:253$260,2005$.

MAUAD, M.; GRASSI FILHO, H.; CRUSCIOL, C.A.C. \& CORRÊA, J.C. Teores de silício no solo e na planta de arroz de terras altas com diferentes doses de adubação silicatada e nitrogenada. R. Bras. Ci. Solo, 27:867-873, 2003.

MICHEL, R.F.M. Solos Criogênicos e Ornitogênicos da área de entorno da Ponta Llano, Antártica Marítima. Viçosa, MG, Universidade Federal de Viçosa, 2005. 146p. (Tese de Mestrado)

MOREIRA, I.M.V. Contribuição ao estudo das Bacillariophyceae (Diatomácceas) em diatomitos brasileiros. Acta Biol. Par., 4:135-198, 1975.

PARR, J.F. \& SULLIVAN, L.A. Soil carbon sequestration in phytoliths. Soil Biol. Biochem., 37:117-124, 2005.

PARRY, D.W. \& SMITHSON, F. Types of opaline silica depositions in the leaves of British grasses. Ann. Bot., 28:169-185, 1964.

PEREIRA, M.C.A. Estrutura das comunidades vegetais de afloramentos rochosos dos campos rupestres do Parque Nacional da Serra do Cipó. Belo Horizonte, Universidade Federal de Minas Gerais. 1994. 163p.(Tese de Mestrado)

PIPERNO, D.R. Phytolith: A comprehensive guide for archaeologists and paleoecologists. Lanham, AltaMira Press, 2006. 238p.

RADAMBRASIL. Levantamento dos recursos naturais: Geologia, geomorfologia, pedologia, vegetação e uso potencial da terra. Folha SB.24/25 Jaguaribe/Natal. Rio de Janeiro, 1981. 740p.

RADAMBRASIL. Levantamento dos recursos naturais: Geologia, geomorfologia, pedologia, vegetação e uso potencial da terra. Folhas SF. 23 / 24, Rio de Janeiro/ Vitória. Rio de Janeiro, Ministério das Minas e Energia, 1983a. 780p.

RADAMBRASIL. Levantamento dos recursos naturais: Geologia, geomorfologia, pedologia, vegetação e uso potencial da terra. Folha SC.24/25 Aracaju/Recife. Rio de Janeiro, 1983b. 839p.

RAMÍREZ S., H.U.; Del V. ZÁRATE, P.F.; GARCÍA, M.E.G.; TORRE V., O.; ISRADE A., I. \& MEULENERT PEÑA, A.R. Disolución de sílice biogênica em sedimentos de lagos utilizados como bioindicadores de calidad del água. Gnosis, 5:1-19, 2007.

RUNGE, F. The opal phytolith inventory of soils in Central Africa - Quantities, shapes, classification, and spectra. Rev. Paleobot. Palynol., 107:23-53, 1999. 
RUIZ-MORENO, J.L. \& CARREÑO, A.L. Diatom biostratigraphy of Bahia Asunción, Baja Califórnia Sur, México. R. Mexicana Ci. Geol., 11:243-252, 1994.

SENDULSKY, T. \& LABOURIAU, L.G. Corpos silicosos de gramíneas dos Cerrados - I. An. Acad. Bras. Ci., 38:159. $185,1966$.

SETZER, A.W.; OLIVEIRA, M.R.; FRANCELINO, M.R.; SCHAEFER, C.E.G.R.; COSTA, L.M. \& BREMER, U.F. Regime climático na Baía do Almirantado: Relações com o ecossistema terrestre. In: SCHAEFER, C.E.; FRANCELINO, M.R.; SIMAS, F.N.B.; ALBUQUERQUE FILHO, M.R., eds. Ecossistemas Costeiros e Monitoramento Ambiental da Antártica Marítima - Baía do Almirantado, Ilha Rei George. Viçosa, MG, Universidade Federal de Viçosa, NEPUT, 2004. p.1-6.

SILVA, S.T. \& LABOURIAU, L.G. Corpos silicosos de gramíneas dos Cerrados - III. Pesq. Agropec. Bras., 5: 167-182, 1970.

STREET-PERROTT, F.A. \& BARKER, P.A. Biogenic silica: A neglected component of the coupled global continental biogeochemical cycles of carbon and silicon. Earth Surface Proc. Landforms, 33:1436-1457, 2008.
STRÖMBERG, C.A.E. Using phytolith assemblages to reconstruct the origin and spread of grass-dominated habitats in the great plains of North America during the late Eocene to early Miocene. Palaeogeogr. Palaeoclimatol. Palaeoecol., 207:239-275, 2004.

TWISS, P.C. Predicted world distribution of $\mathrm{C} 3$ and $\mathrm{C} 4$ grass phytoliths. In: RAPP JR., G. \& MULHOLLAND, S.C., eds. "Phytolith systematics. Emerging issues." Adv. Archaeol. Museum Sci., 1:113-128, 1992.

TWISS, P.C.; SUESS, E. \& SMITH, R.M. Morphology classification of grass phytoliths. Am. Soc. Soil Sci. Proc., 33:109-115, 1969

YIM, W.W.S. \& LI, J. Diatom preservation in an inner continental shelf borehole from the South China Sea. J. Asian Earth Sci., 18:471-488, 2000.

YEOMANS, J.C. \& BREMNER, J.M. A rapid and precise method for routine determination of organic carbon in soil. Comm. Soil Sci. Plant Anal., 19:1467-1476, 1988. 